\title{
The Initiation
}

\section{Publication Coordination Committee}

Coordinator

Ms. Richa Niraula

Members

Mr. Sunny Jha

Mr. Roshan Raj Kafle

Mr. Bharat Sharma

Mr. Shrawan Basnet

Advisory Board

Dr. Uday Raj Sharma

Dr. Keshav Dutta Awasthi

Dr. Bishnu Hari Pandit

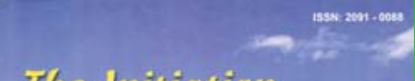

The Initiation

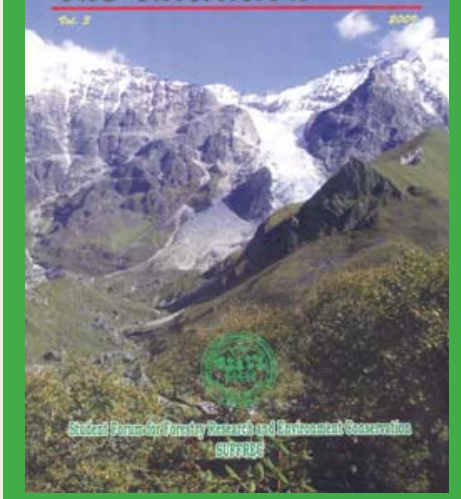

Third Issue of The Initiation

\section{Preface}

"A single step taken in the right direction leads to the success and every journey begins with a single step'- with this view clearly set on the minds, we, Student Forum for Forestry Research and Environment Conservation (SUFFREC), started a platform or probably the link, that brings the scattered beads of knowledge into a common place from the diversified and dignified sources, from academicians to the innovative learners, from researchers to the nature lovers, and enrich what we already have and we pursue to. We are hence, continuously learning and marching to bring out the best of what is needed today. We are trying to raise the unseen and unheard issues of forestry, environment as a whole. We are trying to give a common voice to the unaddressed part of the environment. And we are trying to fight these all with the powerful words, with the large arena of the contributors we have.

It's a common human trend to follow what is there at high. While doing so, and while blindly following others, we several times overlook our needs, our problems and our ground reality. This implies largely to the sector of natural sciences, including, of course, environmental issues and forestry. But, we believe, this has to be changed, and a new wider angle of viewing is needed. With this pious spirit, we gave birth to our journal, The Initiation. And we are still continuing our journey to bring out all the hidden issues and to provide a starting point to the creative beginners which the name of our journal advocates for itself.

Ours is a country blessed with the natural resources. But at the same time, being in the range of Hindu Kush Himalayas makes us vulnerable to the mighty effects of climate change. Similarly, we have to pay for the deeds of other developed countries where the cost is a great loss of biodiversity. It is well known that a country in its liquid state has a lot of problems, but where the political instability becomes a major problem, the environmental issues are mostly, overshadowed. This has clearly been reflected in our losing of the foreign donations and grants in environmental sector. Yet, amidst all the difficulties and uncertainties, growing awareness among the people regarding environment is highly appreciated, especially, that shown by the user groups. However, scientific management and research works are still lacking and those that have been carried out many a time, remain undocumented. The Initiation aims to bridge this gap.

In this issue, we have tried to compile diverse researches and new subjects, so as to provide a compact dose of information, highly sought after. We have opted for a qualitative concise issue rather than a bulky one with lesser quality. There are eighteen articles categorized into three groups- research, review and information. This classification will provide the readers to get a quick glimpse of what is there and make them easier to go through. To support the tourism year, we have also included an article about tourism at community level.

The research category begins with the article by Dr. Mukesh Chalise and consists six articles in total while review category consists four articles with the opening one by Jhamak Karki. Our final category, information, consists eight articles with the $1^{\text {st }}$ article by Hem Sagar Baral. In this issue, we have also included a thesis from the B.Sc pass out student so as to encourage the new ideas.

There are many challenges in forestry sector and many problems have always remained unaddressed. We, through this issue, have tried to bring them out and make them reach the concerned authorities. We hope this issue will meet the needs of knowledge seekers and enrich the great treasury of forestry and nature conservation, thereby standing firmly in meeting the noble objectives of SUFFREC. We expect your cooperation and appreciation for this issue of The Initiation, as always. 